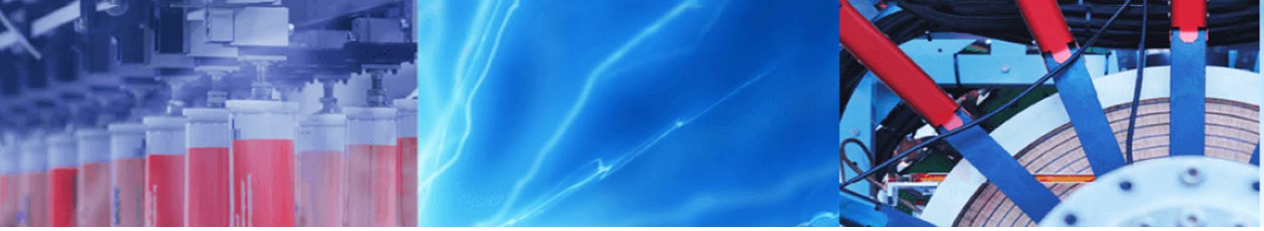

Research Article

\title{
Comparative study on the reservoir operation planning with the climate change adaptation
}

\author{
Nurul Nadrah Aqilah Tukimat ${ }^{1,2}$ (D) $\cdot$ Sobri Harun ${ }^{3}$
}

(c) Springer Nature Switzerland AG 2019

\begin{abstract}
The management planning of Pedu-Muda reservoir, Kedah, was investigated in the context of the climate change evolution. The aim of this study was to evaluate the impact of the climate change to the reservoir operating management system and its sustainability. The study was divided into two sections; Analysis 1 refers to the reservoir optimization adapted with the climate assessment. The statistical downscaling model reacted as the climate model to generate the long-term pattern of the local climates affected by the greenhouse gases. Analysis 2 refers to the reservoir optimization but excluded the climate changes assessment in the analyses. The non-dominated sorting genetic algorithm version II (NSGA-II) was applied in both analyses to optimize the water use due to the multi-objectives demand, maximizing water release, minimizing water shortage and maximizing reservoir storage. The formation of Pareto optimal solutions from both analyses was measured and compared. The results showed the Analysis 1 potential to produce consistence monthly flow with lesser error and higher correlation values. It also produced better Pareto optimal solution set and considered all the objectives demands. The NSGA-II also successfully improves and re-manages the reservoir storage efficiently and reduce the dependancy of these reservoirs.
\end{abstract}

Keywords Non-dominated sorting genetic algorithm $\cdot$ Linear programming $\cdot$ Climate change $\cdot$ Reservoir optimization . Irrigation demand

\section{Introduction}

As the earth warms, storage water in the reservoir is expected to change due to the availability, timing and water quality effects by the global warming or climate variability. The heat rising day by day encourages evaporation to occur faster than in the normal condition contributing to the drought and flood events in critical areas. Additional natural activities such as increasing losses due to high evaporation rate on the water surface, wastage due to the water transfer activity, seepage and infiltration into the underground may reduce the capability of the reservoir. The profitability of the reservoir is also more difficult to achieve if real-time operation is still implemented on the field. The weakness of this operation is that the water release decision was based on the previous experience of water manager and it was not applicable in the critical condition of climate. The situation worsens if they have poor data and there is a lack of information regarding to the reservoir operation, maintenance and capacity. The difficulty often enlarges owing to multi-use reservoir that attempts to achieve optimal water allocation for various uses. Therefore, the risk analysis must be done to solve all uncertainties problems in the real-time operation system [15].

$\square$ Nurul Nadrah Aqilah Tukimat, nadrah@ump.edu.my; Sobri Harun, sobriharun@utm.my | ${ }^{1}$ Faculty of Civil Engineering and Earth Resources (FKASA), Universiti Malaysia Pahang, 26300 Gambang, Malaysia. ${ }^{2}$ Earth Resources and Sustainable Centre (ERAS), Universiti Malaysia Pahang, 26300 Gambang, Malaysia. ${ }^{3}$ School of Civil Engineering, Faculty of Engineering, Universiti Teknologi Malaysia, 81310 Skudai, Johor, Malaysia. 
The connection scenarios between climate and water resources were evaluated and proved by many researchers at different study areas. Duran-Encalada et al. [4] revealed that the $5 \%$ change in temperature and $20 \%$ of rainfall deduction will cause the water deficit in the year 2038. Meanwhile, [1] state that the uncertainty of climate brought large impact to the downstream runoff at Nierji Reservoir, Northeast China. The increment of $1{ }^{\circ} \mathrm{C}$ temperature causes the deduction of $<1 \%$ of mean monthly runoff during reservoir operation. Shaaban et al. [12] projected the changing future of annual precipitation and temperature pattern in Malaysia and estimated an increase in the frequency and severity of droughts and floods at specific locations. The modification of the reservoir operation including the size and number of dams can be a significant solution in facing the vulnerability of water resources system [5].

Changes in the hydrological regimes will have positive and negative impacts on the reservoir systems depending on how it is used and managed. The reservoir optimization methods are using widely the water resources planning for sufficient capacity and capability of storage. Therefore, a multi-objective evolutionary algorithm (MOEA) has been proposed by various authors as an aid to the decision makers in managing the reservoir system efficiently, especially in multi-objective demands $[6,14]$. Moreover, MOEAs have the ability to find multiple Pareto optimal solutions in one single simulation run compare to the classical optimization methods that do not consider all objectives simultaneously by using weighted approach or constrained approach.

Thus, the study aims to evaluate the impact of local climate change on the reservoir operating management system using one of the famous MOEAs, NSGA-II. The case study was evaluated based on two different analyses: Analysis 1 (including climate assessment) and Analysis 2 (excluding climate assessment).

\subsection{Reservoir optimization}

\subsubsection{Non-dominated sorting genetic algorithm (NSGA-II)}

NSGA-II is a modification of genetic algorithm (GA)-based concept in producing better approximation of Pareto optimal front in a single run. It was proposed by [3] to overcome several problems from other evolutionary algorithm (EA) model, which have high computational complexity of non-dominated sorting, have lack of elitism and need to specify the share parameter. It also can assess optimal quantities and reduce the time needed to reach the optimal quantity of decision variables [14]. The upgraded version of these GAs, NSGA-II, becomes the most popular method among multi-objective optimization by EAs, and the potential has been proved by ([10]; [7]; [2]) in their study.

Generating set of Pareto optimal solutions, NSGA-II uses five major steps-initialization, generation of initial population, non-domination sorting, criterion to prepare population for next generation and selection of best compromise solution [3]. The steps are discussed below:

1. Initialization Parent population $\left(P_{t}\right)$ is initialized based on two different parents' chromosome to create a new offspring $\left(Q_{t}\right)$. Here, the parent is referred to as the water demand of Pedu-Muda reservoir.

2. Generation of initial population $P_{t}$ and $Q_{t}$ are randomly combined by using tournament selection to form a new population, known as $R_{t}$.

3. Non-domination sorting $R_{t}$ undergoes non-dominated sorting to classify the entire population. The solution that is not dominated by others is classified as nondominated fronts.

4. Criterion to prepare population for next generation Crowding distance is calculated and ranked according to the boundaries of objectives values. A lower rank and higher crowding distance is the selection criteria. The crossover process is carried out to create new solutions which have some of the attributes of their parents.

5. Selection of best compromise solution Mutation process is conducted to provide new genetic material in finding better global optimization solution and produce new population $Q_{t+1}$.

The steps are repeated until the termination criteria are satisfied. The optimization operation is handled by GANetXL to solve complex optimization and search problems.

1.1.1.1 Analysis 1 The SDSM was used to downscale the global circulation model (GCM) output to project future climate change in the study area. It calculates the statistical relationships between large-scale and local climate variables based on multiple linear regression techniques. The downscaling using SDSM requires two types of data, viz. predictand and predictor. In the present study, historical rainfall (1961-1990) recorded at twenty locations and temperature (1972-2008) recorded at one station of Kedah (Fig. 2) were used as predictand, and the National Center for Environmental Prediction (NCEP) reanalysis data of the study area for the time period of 1961-2008 were used as the predictor. For downscaling of rainfall, the model was calibrated for the time period of 1961-1975 and validated for the period of 1976-1990. For downscaling of temperature, the model was calibrated for the time period of 1972-1999 and validated for the period of 2000-2008. GCM outputs 
of the Hadley Center General Circulation Model (HadCM3) under A2 scenario for the period of 2010-2100 were used for projecting future rainfall and temperature. The A2 scenario chosen for this study provides an upper bound on future emissions, and it is selected from an impacts-andadaptation point of view; if it is adaptable to large climate change, it will have no problem with smaller climate change and lower end scenario, although low emission scenario gives less information from this point of view (NARCCAP 2007).

Next, a hydrological model was used to simulate the water streamflow under projected change in climate known as the Identification of unit Hydrographs and Component flows from Rainfall, Evaporation and Streamflow (IHACRES). It characterizes the dynamical relationship between rainfall and streamflow by using rainfall and temperature (potential evaporation) data to predict time series of streamflow. IHACRES is preferred because it has a simple structure and parsimonious parameterization. Thus, it provides parametric efficiency and statistical rigor in presenting the dynamic response characteristics of the catchment area [9]. The model consists of a nonlinear loss module and a linear unit hydrograph module. The nonlinear loss module calculates the effective rainfall $\left(u_{k}\right)$ from observed rainfall $\left(r_{k}\right)$ for every time step $k$. The linear unit hydrograph module estimates streamflow $\left(x_{k}\right)$ from effective rainfall by using the equations given below:

$x_{k}=a x_{(k-1)}+b u_{k}$

$u_{k}=r_{k} s_{k}$

$s_{k}=C r_{k}+\left(1-\frac{1}{\tau_{w}\left(t_{k}\right)}\right) s_{(k-1)}$

$\tau_{w}\left(t_{k}\right)=\tau_{w} e^{0.062 f\left(R-t_{k}\right)}$

where $a$ and $b$ are the parameters of unit effective rainfall in a linear unit hydrograph module with $b>0$ and $-1<a<0 ; u_{k}$ is refer to the effective rainfall; $s_{k}$ is known as catchment wetness index which value ranges between $0<s_{k}<1 ; \tau_{w}$ is a catchment drying time constant; $R$ is a reference temperature; $t_{k}$ is a monthly temperature; $C$ is a proportion of the rainfall; and $f$ is a temperature modulation factor [11]. The runoff at Pedu-Muda reservoir was calibrated for the time period of 1988-1993 and validated for the time period of 1995-2000. Its performance was then evaluated using the determination coefficient $(D)$ and percentage of average relative parameter error (\% ARPE). These two values are calculated using the following equations:

$D=1-\frac{\sum(x-\hat{x})^{2}}{\sum(x-\bar{x})^{2}}$
$\%$ ARPE $=\frac{1}{n} \sum_{i=1}^{n} \frac{\left(x_{\text {estimated }(i)}-x_{\text {observed }(i)}\right)}{x_{\text {observed }(i)}} * 100$

where $x$ refers to the streamflow, $\bar{x}$ is the mean of streamflow, $\hat{x}$ is error in the predicted streamflow, and $n$ is the size of streamflow. A high D and low \% ARPE indicates that the model has been well calibrated and validated. The projected rainfall and temperature data were used to simulate the streamflow from year 2010 to 2100 .

Next, a crop water model was used in this study to estimate future change in crop water demand at the region. The paddy fields at the Muda Irrigation Scheme are cultivated twice a year; the first season starts in March and ends in August, while the second starts in September and ends in January the following year. Water is supplied three times in three different phases (Phase I, II and III) every season. CROPWAT 8.0 was applied to calculate the total irrigation water requirement using the following equation:

$W_{\text {irr }}=\mathrm{ET}_{\text {crop }}+W_{\mathrm{lp}}+W_{\mathrm{ps}}+W_{\mathrm{l}}-P_{\mathrm{e}}$

where $W_{\text {irr }}$ is the irrigation water requirement; $\mathrm{ET}_{\text {crop }}$ is the crop evapotranspiration; $W_{\mathrm{lp}}$ is the water required for land preparation; $W_{\mathrm{ps}}$ is the percolation and seepage losses of water from paddy field; $W_{1}$ is the water required to establish standing water layer; and $P_{\mathrm{e}}$ is the effective precipitation. Crop evapotranspiration is calculated as:

$\mathrm{ET}_{\text {crop }}=\mathrm{EC} \times \mathrm{ET}_{\text {ref }}$

where $\mathrm{EC}$ is the crop coefficient and $\mathrm{ET}_{\text {ref }}$ is the reference evapotranspiration. The Penman method is used to calculate the reference evapotranspiration from climate data. The effective rainfall is considered as a dependable rainfall event, as suggested by FAO, using the following equation:

$P_{\text {eff }}=0.6 * P-10 / 3 \quad$ for $P($ month $) \leq 70 / 3 \mathrm{~mm}$

$P_{\text {eff }}=0.8 * P-24 / 3$ for $P$ (month) $>70 / 3 \mathrm{~mm}$

Other parameters such as water required for land preparation and losses from paddy field are calculated from soil information. The irrigation demand in this study, is taken as $80 \%$ supplied by the Pedu-Muda reservoirs and the remaining $20 \%$ was contributed by uncontrolled river flow. The prediction of monthly water demand for paddy field is used in this analysis for optimization purpose. The results produced by these steps are remarked as Analysis 1 that practically concern the climate impact assessment.

1.1.1.2 Analysis 2 A sequence flow of Pedu-Muda reservoir was generated using spatial disaggregation technique-Valencia-Schaake (V\&S) method. This method was selected due to its ability in dividing annual flow into finer-scale time series (in month) within each year based on cross-correlation concept. The undemanding data 
series, easier understanding and simple application have made V\&S a well-liked method in recent years. Besides, the method can generate unlimited stochastic flow by the use of limited historical flow time series. The potential of $\mathrm{V} \& \mathrm{~S}$ among other available disaggregation techniques was proved by Ismail et al. [8]. The basic form of V\&S is:

$Y_{t}=A Q_{t}+B \varepsilon_{t}$

where $Y_{t}$ is a seasonal flow value of $Q_{t} ; Q_{t}$ is annual flow value of year $t ; \varepsilon_{t}$ refers to the $m \times 1$ matrix of independent standard normal deviates; $A$ and $B$ refer to the parameter matrices with dimensions of $m \times 1$ and $m \times m$, respectively, by methods of moment (MOM) with $m$ is the 12 months in a year. The parameter matrices of $A$ and $B$ were estimated by equation below:

$A=M_{0}(Y Q) M_{0}^{-1}(Q)$

$B B^{T}=M_{0}(Y)-M_{0}(Y Q) M_{0}^{-1}(Q) M_{0}(Q Y)$

In Analysis 2, Stochastic Analysis Modeling and Simulations (SAMS) developed by [13] was applied to simulate the stochastic time series of flow for the Pedu-Muda reservoir during year 1972-2099. However, the analysis was exclude the climate assessment and loss factors on the site study. This outcome was used as data input in the NSGA-II optimization.

The generated inflows produced by Analysis 1 and Analysis 2 were compared, and the accuracy was measured by using various statistical parameters below:

Mean $=\frac{\sum X_{\text {est }, i}}{n}$

MAE $=\frac{1}{n} \sum\left(X_{\text {est }}-X_{\text {obs }}\right)$

MSE $=\frac{1}{n} \sum\left(X_{\text {est }}-X_{\text {obs }}\right)^{2}$

$\mathrm{SD}=\sqrt{\frac{1}{n} \sum\left(X_{\text {est }}-\overline{X_{\text {est }}}\right)^{2}}$

Skew $=\frac{\frac{1}{n} \sum\left(X_{\text {est }}-\overline{X_{\text {est }}}\right)^{3}}{\mathrm{SD}^{3}}$

$\mathrm{CV}=\frac{\mathrm{SD}}{\bar{X}}$

$\mathrm{cC}=\frac{n \sum\left(X_{\text {est }} X_{\text {obs }}\right)-\left(\sum X_{\text {est }}\right)\left(\sum X_{\text {obs }}\right)}{\sqrt{n\left(\sum X_{\text {est }}^{2}\right)-\left(\sum X_{\text {est }}\right)^{2}} \sqrt{n\left(\sum X_{\text {obs }}^{2}\right)-\left(\sum X_{\text {obs }}\right)^{2}}}$ where $X_{\text {est }}$ and $X_{\text {obs }}$ refer to the monthly flow estimated and observed, respectively; $\bar{X}$ refers to the mean of flow; $\mathrm{SD}, \mathrm{CV}$ and CC indicate the standard deviation, co-variance and correlation coefficient, respectively.

1.1.1.3 Reservoir optimization The NSGA-Il was applied by using Analysis 1 and Analysis 2 fit to the multi-objectives purposes; (1) first is to optimize the reservoir operation so that the monthly supply can be maximized to meet the irrigation demand of the paddy fields. The amount of water supplied depends on the availability of monthly Pedu reservoir storage. (2) Second is to minimize water shortage, which is equivalent to the sum of monthly water shortage within a year. (3) Third is to maximize monthly reservoir storage after considering the release and other loses from the reservoir storage. In the NSGA-II model, the optimal Pareto front was obtained from a Pareto set of 150 populations (the maximum population of chromosomes available in GANetXL) after running 1000 generations. The crossover and mutation rate were set as 0.95 and 0.06 , respectively. Five constraints were set for 12 months to get the optimal Pareto front. The objective functions, formulated for 12 months, are mentioned as:

Maximize $\sum_{t=1}^{12} R_{t}$

Minimize $\sum_{t=1}^{12}\left(D_{t}-R_{t}\right)$

Maximize $\sum_{t=1}^{12} S_{t}$

The constraints can be equated by using the following mass balance equation:

$S_{(t+1)}=S_{t}+P_{t}+I_{t}-E v a_{t}-R_{t}-S e e_{t}-S p_{t}+S_{\text {muda }}$

$S_{\min } \leq S_{t} \leq S_{\max }$

$R_{\text {min }} \leq R_{t} \leq R_{\text {max }}$

$D_{t} \leq R_{t}$

where $R_{t}$ is the water released by reservoir in period $t ; D_{t}$ is the irrigation demand in period $t ; S_{t}$ refers to the Pedu reservoir storage at end of the $t$ th month; $S$ refers to water storage at Pedu reservoir; $P_{t}$ is the rainfall amount in period $t ; l_{t}$ is the inflow into the reservoir in period $t ; S p_{t}$ is the water spill for the period $t$ when the reservoir storage exceeds the limit; and $\mathrm{Eva}_{t}$ and $\mathrm{See}_{t}$ are the evaporation and seepage losses from reservoir in period $t$. 
Additional constraints had also been set to minimize water transfer from the Muda reservoir when the Pedu reservoir has insufficient water storage and to minimize water spill from the Pedu reservoir when the stored water exceeds monthly reservoir capacity.

Water transfer from Muda reservoir $=$ If $\begin{cases}S_{t}<S_{\min } & 0 \\ S_{t}>S_{\min } & S_{t}-S_{\min }\end{cases}$

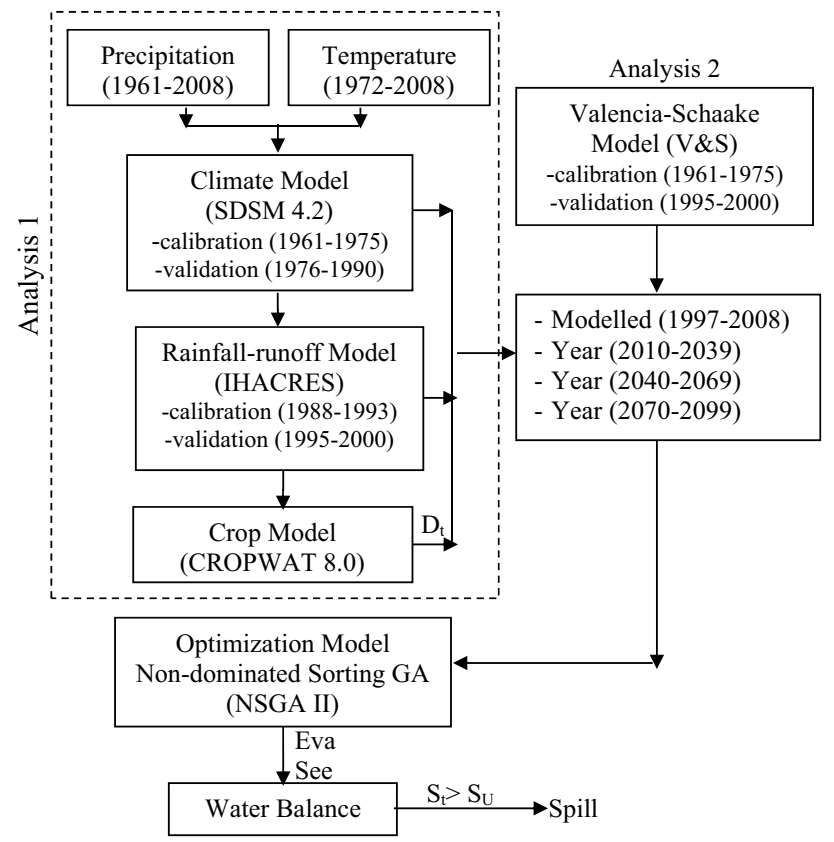

Water spill, $S P_{t}=$ If $\begin{cases}S_{t}<S_{\text {capacity }} & 0 \\ S_{t}>S_{\text {capacity }} & S_{t}-S_{\text {capacity }}\end{cases}$

The detailed procedure is illustrated in Fig. 1.

\section{Study region}

Pedu-Muda reservoirs were located in Kedah state, Northern of peninsular Malaysia. These reservoirs mainly supply water to the Muda Irrigation Scheme which the largest paddy cultivation area in Malaysia. Practically, Pedu reservoir acts as the main water storage to supply the required water of paddy field meanwhile Muda reservoir acts as the backup water storage of Pedu reservoir. It connected to the farmer through a $6.8 \mathrm{~km}$ of Saiong tunnel.

Figure 2 shows the detail location of the study. The area of Muda Irrigation Scheme was 97,000 hectares. Geographically, the area lies between $5^{\circ} 45^{\prime}-6^{\circ} 30^{\prime} \mathrm{N}$ latitude and $100^{\circ} 10^{\prime}-100^{\circ} 30^{\prime} \mathrm{E}$ longitude. The area was almost flat with a slope ranging from 1 in 5000 to 1 in 10,000. The soil was heavily clayey in nature. The area's climate can be classified into four seasons, viz. southwest monsoon (May-September), northeast monsoon (November-March) and two intermonsoon seasons. December-February and June-July were considered as warm seasons, while April-May and September-November are humid seasons. The mean temperature in the area varies between 27 and $32{ }^{\circ} \mathrm{C}$. The relative humidity fluctuates between 54 to $94 \%$.

Fig. 1 Flowchart showing the procedure used in the study

Fig. 2 Location of Pedu-Muda reservoirs in Kedah state of Malaysia. Rainfall station: KOD: Kodiang; JIT: Jitra; LTP: Ladang Tanjung Pauh; KN: Kuala Nerang; AP: Ampang Pedu; GM: Gajah Mati; TC: Teluk Chengai; KT: Keretapi Tokai; KS: Kuala Sala; PEN: Pendang; KSS: Kota Sarang Semut; SL: Sg. Limau; KP: Kedah Peak; SG: Sg. Gurun; IBT: Ibu Bekalan Tupah; LH: Ladang Henriatta; SIK: Sik; Kg.LS: Kg. Lubuk Segintah; Kg. T: Kg. Terabak; Kg.LB: Kg. Lubuk Badak

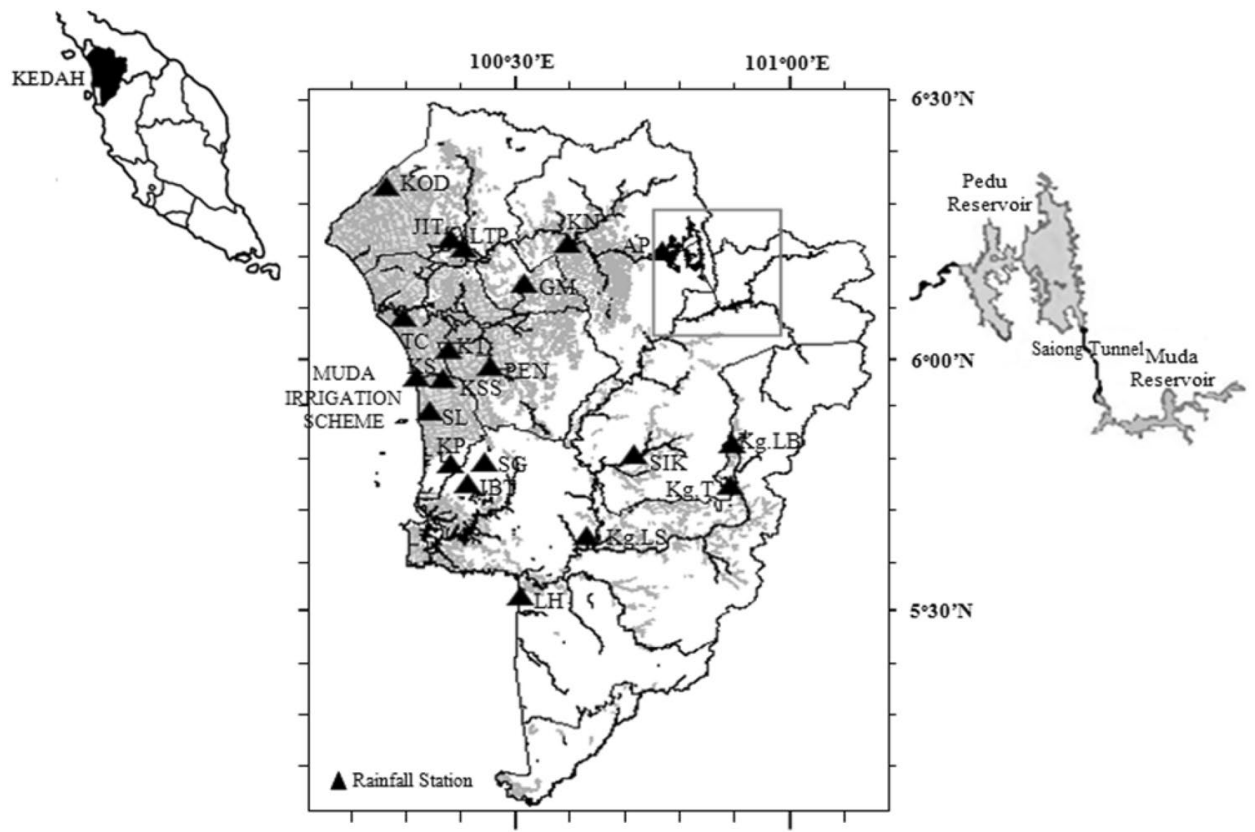

SN Applied Sciences A SPRINGER NATURE journa 


\section{Results and discussion}

\subsection{Climate simulation}

This research work utilized the SDSM to project climate changes at every station by using multiple regression equation that relates the observed rainfall and temperature with large-scale atmospheric variables. It has been found that the large-scale atmospheric variables, viz. $500 \mathrm{hPa}$ zonal velocity, airflow strength, $500 \mathrm{hPa}$ relative humidity, $850 \mathrm{hPa}$ meridional velocity and specific humidity are related to the rainfall and temperature of the area. Therefore, these variables were used to derive the multiple regression equations. The mean absolute error (MAE),

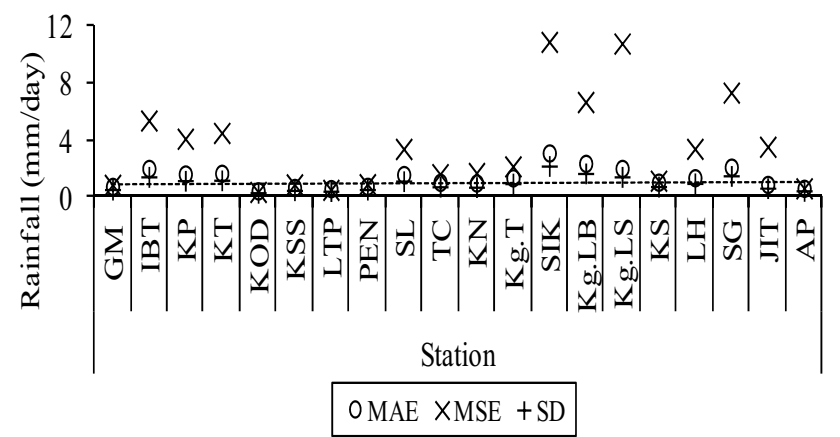

Fig. 3 The mean absolute error (MAE), mean square error (MSE) and standard deviation (SD) in predicted rainfall at each station mean square error (MSE) and standard deviation (SD) of the downscaled rainfall at each station are graphically illustrated in Fig. 3. Although the errors in the predicted results were slightly higher at several stations such as Sik and $\mathrm{Kg}$ Lubok Segintah, it is still reasonable and accepted. The average SD for the predicted rainfall at all stations reached 1.0 and proved the dispersion of modeled rainfall strongly closed to the historical data.

Figure 4 shows the spatial distribution of projected rainfall obtained through climate downscaling for the interval year of $\Delta 2020, \Delta 2050$ and $\Delta 2080$, i.e., increment and decrement of rainfall intensity in different areas. The average annual rainfall was expected to increase significantly to $2644 \mathrm{~mm}(\Delta 2020), 2944 \mathrm{~mm}(\Delta 2050)$ and $3717 \mathrm{~mm}$ $(\Delta 2080)$. Moreover, the province's seasonal rainfall distribution was expected to scale during northeast monsoon, specifically in November, December and February to April.

The annual rainfall surrounding Pedu-Muda reservoirs was expected to increase continuously until year of 2099. The climate downscaling model revealed the annual rainfall near to Pedu-Muda reservoirs was expected to increase up to $3160 \mathrm{~mm}$ in $\Delta 2080$ (30\% from the historical record). However, the rainfall at Pedu-Muda reservoirs was expected to decrease in particular months. At Muda reservoir, the rainfall was projected to decrease from June to August and increase in other months with the highest increase happening in February. The rainfall at Pedu reservoir was also expected to decrease between Jan and May and increase in other months. The highest increment occurred in August.
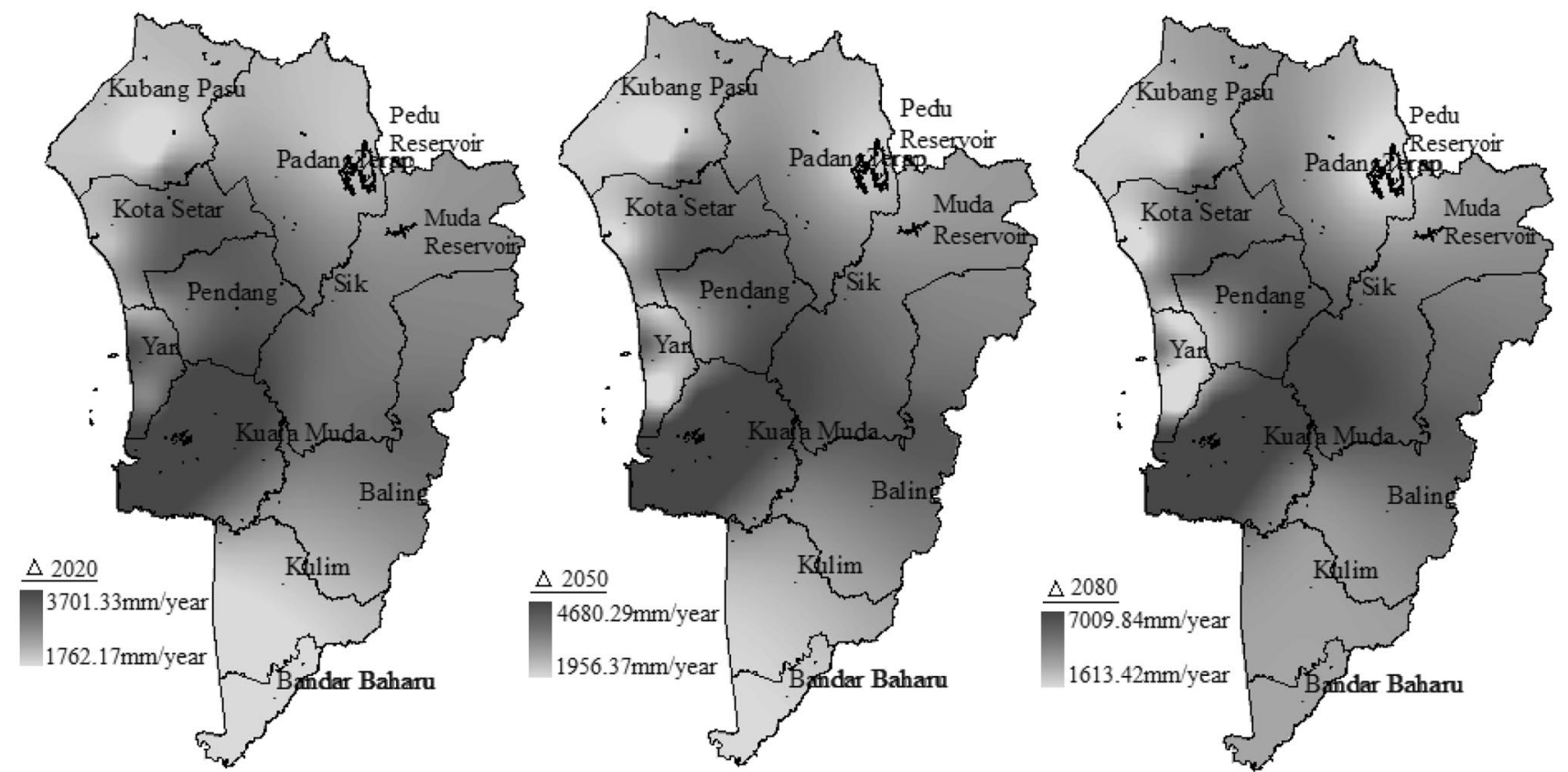

Fig. 4 Spatial distribution of projected annual average rainfall in Kedah in the years 2020, 2050 and 2080 
The simulated results of temperature and water demand at the Muda Irrigation Scheme are shown in Fig. 5. Results indicated that the study area's average temperature continued to rise by $0.2^{\circ} \mathrm{C}$ per decade. The maximum temperature was expected to rise $7 \%$ and may reach up to $37.6^{\circ} \mathrm{C}$ at the end of this century. Meanwhile, the mean temperature was constantly $27^{\circ} \mathrm{C}$ during southwest monsoon (June to September), but it was increasing continuously during northeast monsoon (February to March).

The water demand estimated by CROPWAT model after considering all factors was $710 \mathrm{MCM} /$ year, $7 \%$ lesser compared to the historical water demand record (762 MCM/ year). Furthermore, it has been simulated that the highest water demand was in the first month of the cultivation season, but this decreased gradually until the end of the season. The average daily $\mathrm{ET}_{\mathrm{c}}$ was found to be more than $4 \mathrm{~mm}$ during cropping seasons. Over the time period, as predicted by the CROPWAT model, the water demand was expected to decrease even though the temperature and evapotranspiration from crop fields scales increased because of increase in rainfall. The decrease in water demand was predicted to be $0.9 \%$ per decade, and this shall leave an impact during the first months of the crop seasons, i.e., March and September.

\subsection{Flow evaluation}

The water inflow for Pedu-Muda reservoir was estimated by using two different analyses (Analysis 1 and Analysis 2). Figure 6 shows the performance of generated inflow between Analysis 1 and Analysis 2 with historical records during year 1995-2000. In Analysis 1, the best stochastic inflow in validation process simulated at $\tau_{w}$ was 6 and at $f$ was 1.6 producing $D$ and \%ARPE values of 0.852 and $0.55 \%$, respectively. The annual average inflow estimated was $980 \mathrm{MCM} /$ year, $+12 \%$ overestimated than historical record ( $876 \mathrm{MCM} /$ year), and the average bias between the modeled and historical data was $2.5 \mathrm{MCM}$. It is postulated that the inconsistency in results may be caused by small sample size. In Analysis 2, the monthly stochastic inflow

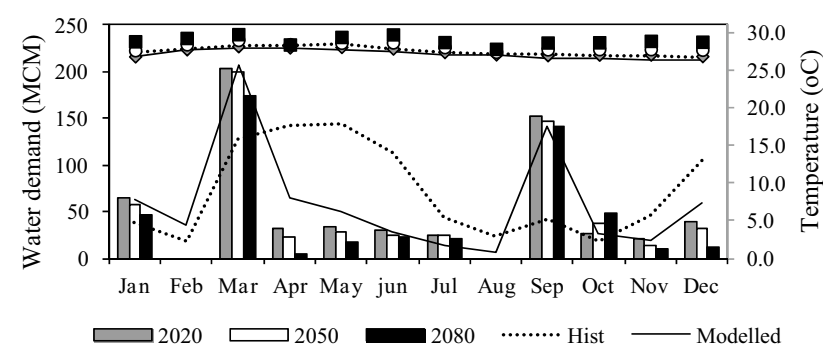

Fig. 5 Projected mean temperature and water demand of PeduMuda Reservoir

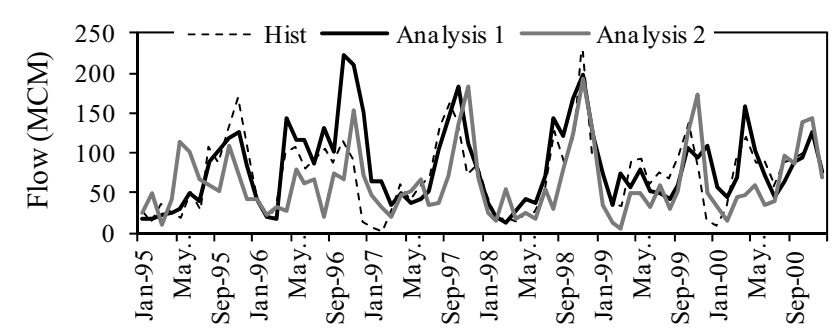

Fig. 6 The validation process of generated flow using Analysis 1 and Analysis 2

was generated for 130 years based on the 31-years length historical record. Due to the validation process, the result indicates the white noise variance (WNV) for this analysis is 0.96. The autocorrelation factor (ACF) is found to be simulated well between historical and generated data at lag 0 with 1.0. Therefore, the average annual inflow produced by this model is $749 \mathrm{MCM} / \mathrm{year},-14 \%$ underestimated than historical record.

Figure 7 shows the performance of Analysis 1 and Analysis 2 due to the mean and MAE against observed data presented in the boxplot and whisker plot graphs. The analysis depends on the 31-years average generated length record. In Fig. 7, the result in Analysis 1 produced smaller spreading (UQ-LQ) at mean and MAE results compared to the Analysis 2 result, evidencing the consistency of monthly data and less error yield. The estimated error produced by Analysis 2 against observed data became larger during October and November to be $5.9 \mathrm{MCM} /$ year. However, the central tendencies for both analyses were closer to the mean observed data.

Supported by the statistical testing shown in Table 1, the performance of generated flow by both analyses was presented in SD, CV, skew and CC values. The results show
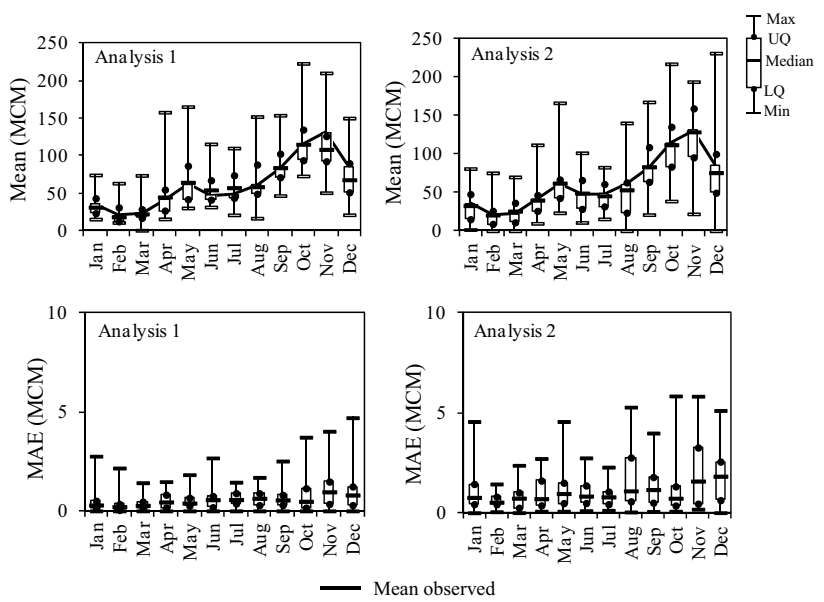

Fig. 7 Mean and MAE results for Analysis 1 and Analysis 2 simulated in flow generation. Note: LQ: low quartile; UQ: upper quartile 
Table 1 Statistics comparison between historical, ValenciaSchaake and modeled simulated results

\begin{tabular}{lccccccccccccc}
\hline & Jan & Feb & Mar & Apr & May & Jun & Jul & Aug & Sep & Oct & Nov & Dec & Annual \\
\hline SD & & & & & & & & & & & & & \\
Hist & 29.9 & 14.2 & 19.7 & 28.7 & 32.5 & 22.6 & 24.1 & 41.4 & 35.1 & 31.4 & 45.2 & 53.1 & 31.5 \\
Analysis 1 & 16.4 & 13.1 & 16.8 & 32.7 & 35.8 & 20.6 & 22.4 & 33.8 & 29.1 & 36.7 & 39.2 & 32.5 & 27.4 \\
Analysis 2 & 21.0 & 16.3 & 19.6 & 23.9 & 32.1 & 24.1 & 17.9 & 36.0 & 32.3 & 37.0 & 41.4 & 47.3 & 29.1 \\
CV & & & & & & & & & & & & & \\
Hist & 0.8 & 0.7 & 0.9 & 0.7 & 0.5 & 0.5 & 0.5 & 0.7 & 0.4 & 0.3 & 0.3 & 0.6 & 0.6 \\
Analysis 1 & 0.5 & 0.6 & 0.6 & 0.7 & 0.5 & 0.4 & 0.4 & 0.5 & 0.3 & 0.3 & 0.3 & 0.4 & 0.5 \\
Analysis 2 & 0.7 & 0.8 & 0.7 & 0.6 & 0.5 & 0.5 & 0.4 & 0.7 & 0.4 & 0.3 & 0.3 & 0.6 & 0.6 \\
Skew & & & & & & & & & & & & & \\
Hist & 2.3 & 0.6 & 2.0 & 1.2 & 1.0 & 1.2 & 0.4 & 1.0 & 0.4 & -0.3 & 0.4 & 0.8 & 0.9 \\
Analysis 1 & 0.9 & 1.4 & 1.5 & 2.2 & 1.2 & 1.0 & 0.3 & 1.0 & 1.0 & 1.0 & 0.8 & 0.5 & 1.1 \\
Analysis 2 & 0.6 & 1.7 & 0.5 & 1.5 & 1.5 & 0.1 & 0.2 & 1.2 & 0.1 & 0.6 & -0.3 & 1.2 & 0.7 \\
CC & & & & & & & & & & & & & \\
Analysis 1 & 0.6 & 0.4 & 0.7 & 0.8 & 0.9 & 0.5 & 0.7 & 0.9 & 0.7 & 0.6 & 0.6 & 0.5 & 0.8 \\
Analysis 2 & -0.1 & 0.0 & 0.0 & -0.1 & -0.2 & 0.0 & 0.0 & -0.2 & -0.2 & -0.2 & 0.2 & 0.0 & -0.1 \\
\hline
\end{tabular}

Analysis 2 produces higher value in SD and CV than the Analysis 1 and closer to the SD and CV of historical result. It proves the dispersion of mean by Analysis 2 more similar to the historical result even both analyses produce similar patterns of observed mean.

The skewness test at $10 \%$ significant was used to identify the asymmetry of the data distribution. The different skewness values for Analysis 1 and Analysis 2 were \pm 0.2 from the historical one. However, the CC result by Analysis 1 gives a positive stronger correlation than Analysis 2. The higher correlation can be seen in May and August when the CC value is 1.0 while CC produced by Analysis 2 was just 0.2 in negative association. Therefore, the result of Analysis 1 was indicated as more reliable/accurate result due to the consistency of monthly flow reading, lesser monthly error and higher value of CC.

\subsection{Optimization simulated results}

In order to solve the optimization model, the NSGA-II was applied to find the optimum solution with considered the water demand results. The decision variables in this study were representing the monthly release amount from Pedu reservoir in million cubic meter (MCM) due to multiple conflict of objectives and constraints. Figure 8 indicates the formation of Pareto front using NSGA-II based on two different analyses (Analysis 1 and Analysis 2) during year 1997-2000. The results show the Pareto front produced by Analysis 2 was infrequent compared to the Analysis 1 which optimized consistently. These analyses produced 150 set of Pareto optimal solution from 1000 of generation.

Figure 8 shows the suggestions of optimal solution due to the multi-objectives demanding by Analysis 2 . The solutions were likely biases to one objective only in the optimization demand, maximizing reservoir storage. Both analyses used the same optimization model, but the formation of Pareto front in Analysis 2 was depending on the generated flow as water inlet for the reservoir storage.

It may reduce the ability of offspring chromosome to satisfy all the goals in non-dominated sorting process. In contrast to the Analysis 1, even the Pareto curve line was lower than the Analysis 2 but it gives a better solution considering all the goals. As example case in year 1999, the historical record stated the total water storage and water demand are 12,136 MCM and 690 MCM, respectively, with no shortage $\left(R_{t}=D_{t}\right)$ with amount of spilled water to be 13.7 MCM in February and March. Using optimization by NSGA-II, the best Pareto solution for Analysis 1 was selected at the highest of curve line and the best Pareto solution for Analysis 2 was selected at the lowest of curve line. The selection was based on the water release capacity $\left(R_{t}>D_{t}\right)$ and the least of water shortage $\left(R_{t}-D_{t}\right)$. The result of Analysis 1 is as follows: water demand =736 MCM (+7\%) and water storage $=10,442$ MCM $(-14 \%)$ with no shortage and no spill occur. In Analysis 2 water demand $=690 \mathrm{MCM}$ $(0 \%)$ and water storage $=9665$ MCM $(-20 \%)$ with no shortage and no spillover. Based on these results, it clearly shows the Analysis 1 was more practically used in improving the reservoir operation system especially in the producing better set of Pareto optimal solution.

\subsection{Water balance and operating rule curve}

Figure 9 shows the rule curves of historical, Analysis 1 and Analysis 2 produced by NSGA-II. The rule curves of Pedu reservoir were designed based on the irrigation needs for paddy field only. The maximum minimum operating level $\left(\mathrm{WL}_{\max }\right)$ and minimum operating level $\left(\mathrm{WL}_{\min }\right)$ 
Fig. 8 Operating rule curve produced by NSGA-II for Pedu reservoirs

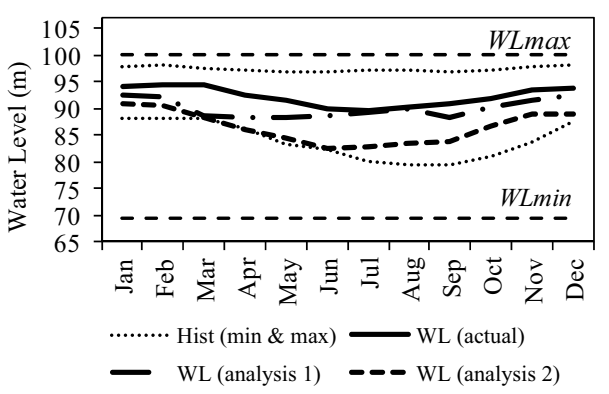

Fig. 9 Operating rule curve produced by NSGA-II for Pedu reservoirs

were considered to control present water storage in the reservoir. Application of the simulation-optimization approach likes NSGA-II for optimization of reservoir operating rules shows significant improvement compared to the historical records. Eventhough the real-time operations produced higher rule curve than the optimization modeling; however the NSGA-II was successfully to use the water storage efficiently. In the Analysis 1, the water level $(\mathrm{WL})$ has potential to increase in July-August and November-February since no water supply was provided during end process of cultivation season (growth stage). Higher water demand supplied during early stage of cultivation; March-April (first season) and September-October (second season). These developed forecasting operations were satisfied because the WL never reached $S_{\min }$.

Analysis 2 shows the WL was dropped to the historical minimum level during March to Jun. It was because the water demand during these months was higher than
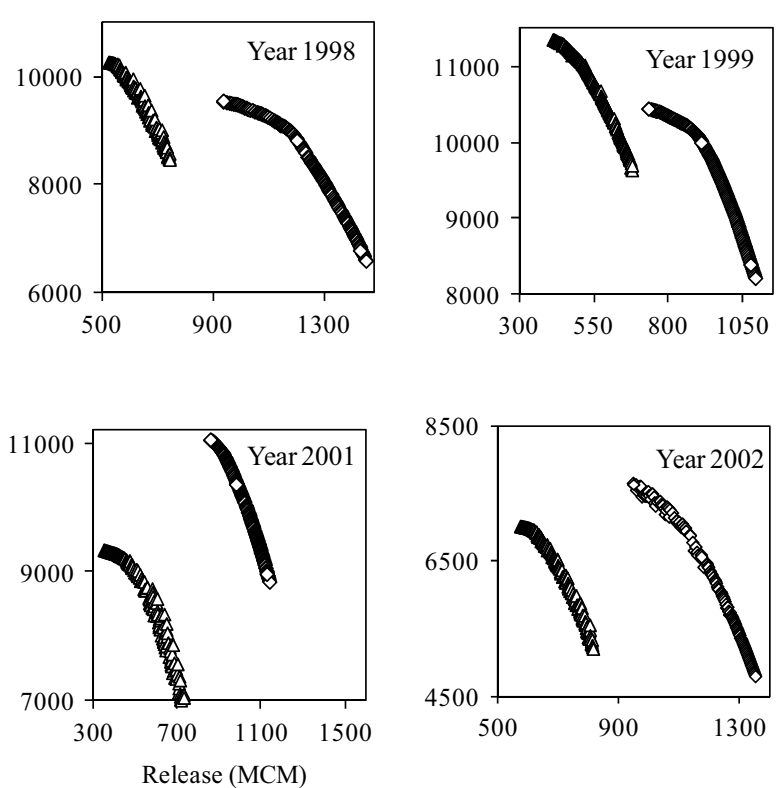

$\diamond$ Analysis $1 \quad \triangle$ Analysis 2

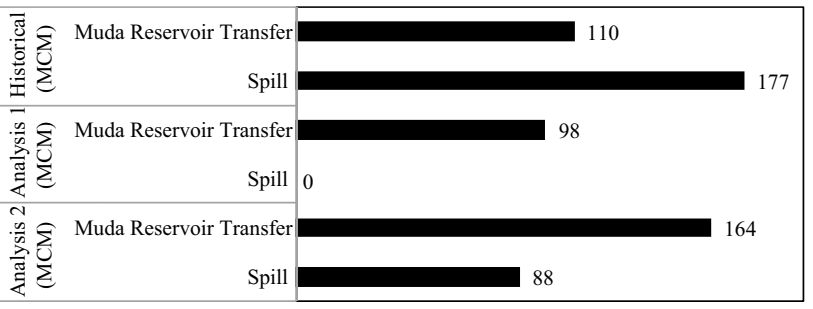

Fig. 10 Estimated $\mathrm{f}$ water transfer from Muda reservoir and spill amount

the estimated water flow that will enter the reservoir. The water deficit may be expected to occur, while it was not supported by rainfall amount in the optimization analysis. However, the analysis in this case still can be accepted because of not passing the minimum requirement of WL.

Figure 10 presents another performance of Analysis 1 and Analysis 2 due to the constraints demanding in Eqs. 23 and 24 . These constraints were used to re-manage the spill amount of that reservoir and water transfer from Muda reservoir. Twelve-year historical record (1995-2008) shows the water transfer from Muda reservoir was released in year 1998 and 2002 with total amount of 110 MCM. Figure 10 shows the implication of re-managing the Pedu reservoir optimization based on two different analyses. The result revealed the Analysis 1 produces better execution than historical record and Analysis 2 because it can reduce amount of water transfer from Muda reservoir (11\%) and no spilled water. The lowest water requirement during year 


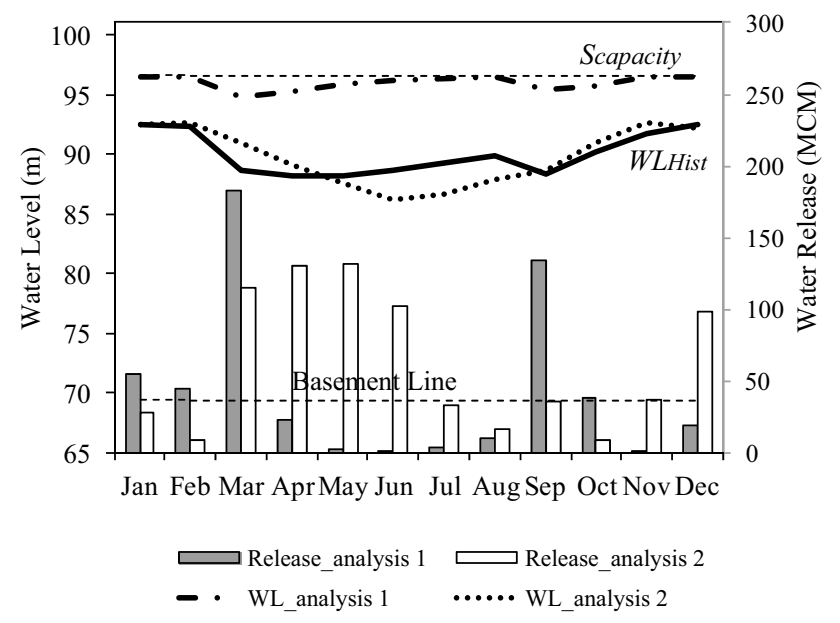

Fig. 11 Proposed water level based on modeled and V\&S simulated result in year 2040-2069

2005 was estimated to 98 MCM which above the minimum reservoir level. The optimization results were successfully to modify the reservoir performance compared to the historical trend. As a remarked, the NSGA-II in Analysis 1 has potential to reduce the dependancy of Pedu reservoir to Muda reservoir storage. It contrast with the Analysis 2 whereby the reservoirs still need each others. For example, Pedu reservoir was expected to require 164 MCM from Muda reservoir to supply sufficient water capacity to the paddy field. It was because the contribution of reservoir storage only depends on the water flow that entered to the reservoir. Therefore, it decreased the capability of the reservoir to supply sufficient water demand for the irrigation purpose. The spillover of water occurred during year 2007 because the water inflow rises and no loss factors were considered.

Figure 11 reveals the proposed monthly water release and WL for Analysis 1 and Analysis 2 using NSGA-II for time period of 2040-2069. The monthly optimum reservoir storage was designed between $200 \mathrm{MCM} /$ month $(69 \mathrm{~m})$ and $1050 \mathrm{MCM} /$ month $(97 \mathrm{~m})$. Considering all the objectives, the water balance can be achieved. The water storage of Pedu reservoir was predicted to achieve its optimal water level using both analyses. The reservoir needs to sustain its capability to supply water especially in early cultivation period. However, Fig. 11 shows Analysis 1 proposed higher WL and water demand for every month than Analysis 2 except in March. During these years, zero water transfer from Muda reservoir and more water spillover were recorded prove by the increment of water inflow and decrement of water demand at study area due to the climate simulation in the future. In the future year, the proportion of irrigation demand for Muda Irrigation Scheme was estimated to change to direct rainfall (80\%), Pedu-Muda reservoir (15\%) and uncontrolled river inflows (5\%) excluding recycle process from water drainage. It was much different from the previous analysis (Loh 2011) that stated the direct rainfall contributed $52 \%$ for the paddy area and the rest comes from uncontrolled flow (10\%), Pedu reservoir (30\%) and recycled drainage water (8\%). Therefore, it can be remarked that the Pedu reservoir will have sufficient storage to fulfill the irrigation demand during the time period of 2040-2069 without any assistance from the Muda reservoir.

\section{Conclusion}

Analysis 1 (operating rule curve with consider all the climate factors) and Analysis 2 (operating rule curve without consider climate factors) have been developed to determine the impacts of climate change on water balance of the reservoir and to optimize the reservoirs' operation accordingly by using NSGA-II model. These analyses were simulated, and the performance results were compared based on statistical tests and the formation of Pareto optimal solution. The results were siding to Analysis 1 because it produced a consistence monthly flow reading, lesser monthly error in MAE test and higher association with the historical records. In the formation of Pareto solutions, Analysis 1 generated better solution considering all the objectives demands than Analysis 2. Considering of climate factors in the analysis may change the water inlet pattern of reservoir storage. Applying NSGA-II in Analysis 1 also can improvised and re-managed the reservoir storage efficiently. As proven, it can reduce the dependability of Pedu reservoir than the Muda reservoir with full use of storage (no spill water) compared to the historical records.

A simple analysis like $V \& S$ (Analysis 2) was very friendly modeling but producing bigger error than Analysis 1 . Besides, Analysis 2 was also produced insufficient optimal solution and only successfully to achieve one optimization's objective without concerned another objectives in the study.

Thus, the climate aspects could be considered in preparing reservoir management. The implication may affect the reliability of the reservoir water supply due to the global climate changes. Practicing NSGA-II amplifies this analysis simulation in producing many optimal solution choices for the decision makers to improve the quality of reservoir system.

Acknowledgements This research was supported by Universiti Malaysia Pahang (UMP) and Ministry of High Education (MHE). 


\section{Compliance with ethical standards}

Conflict of interest The authors declare that they have no conflict of interest.

\section{References}

1. Baohui M, Huanlong L, Wei T, Zhijian W, Ji H (2019) The impact of reservoirs on runoff under climate change: a case of Nierji reservoir in China. Water 11:1-21

2. Chang FJ, Wen-Ping T, Yu-Chung W, Pin-An C, Li-Chiu C, Alexandra C, Georges V (2014) Optimal reservoir operation strategy for balancing ecosystem and human needs. In: Hydrology in a changing world: environmental and human dimensions proceedings of FRIEND-water 2014, Montpellier, France, October 2014 (IAHS Publ. 363, 2014)

3. Deb K, Pratap A, Agarwal S, Meyarivan T (2002) A fast and elitist multiobjective genetic algorithm: NSGA-II. IEEE Trans Evol Comput 6:182-197

4. Duran-Encalada JA, Paucar Caceres A, Bandala ER, Wright GH (2017) The impact of global climate change on water quantity and quality: a system dynamics approach to the US-Mexican transborder region. Eur J Oper Res 256(2):567-581

5. Ehsani N, Vorosmarty CJ, Fekete BM, Stakhiv EZ (2017) Reservoir operation under climate change: storage capacity options to mitigate risk. J Hydrol 555:435-446

6. Hassaballah K, Jonoski A, Popescu I, Solomatine DP (2012) Model-based optimization of downstream impact during filling of a new reservoir: case study of Mandaya/Roseires reservoirs on the Blue Nile river. Water Resour Manag 26(2):273-293

7. Hojjati A, Monadi M, Faridhosseini A, Mohammadi M (2018) Applications and comparison of NSGA-II and MOPSO in multi-objective optimization of water resources system. J Hydrol Hydromech 66(3):323-329

8. Ismail NA, Harun S, Yusop Z (2004) Synthetic simulation of streamflow and rainfall data using disaggregation models. Jurnal Kejuruteraan Awam 16(2):56-65

9. Jakeman AJ, Hornberger GM (1993) How much complexity is warranted in a rainfall runoff model. Water Resour Res 29:2637-2649

10. Kang L, Zhang S, Ding Y, He X (2016) Extraction and preference ordering of multireservoir water supply rules in dry years. Water $8(28): 1-18$

11. Littlewood IG, Down K, Parker JR, Post DA (1997) IHACRES v1.0 user guide. Centre for Ecology and Hydrology, Wallingford, UK \& Integrated Catchment Assessment and Management Centre, Australian National University, Canberra

12. Shaaban AJ, Amin MZM, Chen ZQ, Ohara N (2012) Regional modeling of climate change impact on peninsular malaysia water resources. J Hydrol Eng 16(12):1040-1049

13. Sveinsson OGB, Salas JD, Lane WL, Frevert DK (2007) Stochastic analysis modeling and simulation (SAMS2007)-user manual

14. Tabari MMR, Soltani J (2013) Multi-objective optimal model for conjunctive use management using SGAs and NSGA-II models. Water Resour Manag 27(1):37-53

15. Yimeng S, Feilin Z, Juan C, Jinshu L (2018) Risk analysis for reservoir real-time optimal operation using the scenario tree-based stochastic optimization method. Water 10(5):606

Publisher's Note Springer Nature remains neutral with regard to jurisdictional claims in published maps and institutional affiliations. 